\title{
Comparison of trunk and spine deformity in adolescent idiopathic scoliosis
}

\author{
Brandon B Carlson, Douglas C Burton ${ }^{*}$ and Marc A Asher
}

\begin{abstract}
Background: Cobb measurement of standing radiographs is the standard for clinical assessment of coronal spinal deformity. Angle of trunk inclination (ATI) is an accepted clinical measurement of trunk asymmetry, and has variable reported correlations with Cobb angles. Transverse plane spine deformity is most accurately measured using axial computed tomography. Aaro and Dahlbourn's technique for quantifying apical vertebral rotation with respect to the sagittal plane (RAsag) is commonly reported in the literature. To our knowledge no study has correlated ATI with RAsag. The purpose of this study was to determine the relationship between commonly used measures of trunk and spine deformity.
\end{abstract}

Methods: Sixteen females that underwent preoperative apical vertebra(e) CT scans were retrospectively studied. Thoracic and thoracolumbar RAsag measurements were date-matched to clinically obtained ATI and Cobb measurements. Two-tailed Pearson correlations were calculated; $a=0.01$.

Results: Median patient age was 14.6 years (11-19); BMI 19.4 (16.0-25.5). Curve patterns: Lenke 1 (5); 2 (5); 3 (1); 4 (1); 5 (2): 6 (2). Twenty-six curves (15T; 11TL) with complete, date-matched data points were analyzed. In thoracic curves, ATI correlated with Cobb $(r=0.711, P<0.004)$ and RAsag $(r=0.730, P<0.003)$. ATI was inversely correlated with Cobb flexibility $(r=-0.647, P<0.01)$. In thoracolumbar curves, ATI correlated with Cobb $(r=0.789, P<0.005)$, and RAsag $(r=0.771, P<0.006)$ but not Cobb flexibility $(r=-0.452, P=0.190)$.

Conclusions: Trunk and spine thoracic and thoracolumbar transverse plane deformity are correlated, as are trunk transverse plane and spine coronal plane deformity. Increasing trunk deformity limits thoracic, but not thoracolumbar spine flexibility.

Keywords: Adolescent idiopathic scoliosis, Computed tomography, Angle of trunk inclination, ATI, Scoliometer

\section{Background}

Adolescent idiopathic scoliosis (AIS) is a three-dimensional deformity of the spinal column and associated rib cage [1]. Coronal and sagittal deformities are typically quantified using 2-dimensional radiographs [2]. Transverse plane vertebral rotation can be assessed using radiographs [2-7], ultrasound [8], and MRI [9], but the gold standard remains axial computed tomography (CT) [10-12].

Trunk deformity is important to both physicians and patients [13]. Many indices of trunk asymmetry exist, each with varying correlations to standard radiographic measurements [14]. The Bunnell Scoliometer is a widely used, non-invasive, clinical method for scoliosis screening
[15]. Physicians use a Scoliometer to quantify trunk asymmetry as Angle of Trunk Inclination (ATI) and monitor deformity progression clinically.

Quantifying multiple deformity parameters pre- and post-operatively is useful for understanding AIS disease progression and management effectiveness. Vertebral rotational correction has gained popularity as a means for improving trunk deformity, however, regular assessment using $\mathrm{CT}$ is limited by radiation exposures and cost.

The purpose of this study was to quantify the relationship between clinically measured ATI and apical vertebral rotation measured on axial computed tomography. To date, no study has correlated ATI and CT-measured vertebral rotation.

\footnotetext{
* Correspondence: dburton@kumc.edu

Department of Orthopedic Surgery, University of Kansas Medical Center, 3901 Rainbow Blvd, Mail Stop 3017, Kansas City, KS 66160, USA
} 


\section{Methods}

This study was approved by the University of Kansas Internal Review Board Human Subjects Committee. It is a retrospective study of prospectively obtained materials for AIS patients treated by a single surgeon (MAA) at a single institution between 1995 and 1998. Inclusion criteria were: 1. Diagnosis of Adolescent Idiopathic Scoliosis 2. Posterioranterior, lateral and side-bending radiographs 3. CT scans with selective slices at the apical vertebra(e) and sacrum 4. Clinic records documenting ATI measurement(s) 5. All materials must be from the exact same date 6 . No previous history of spinal surgery.

Patient curves were defined by Lenke's classification [16]. Coronal and side-bending Cobb angles were measured by a single investigator (BBC). Vertebral rotation was measured on axial CT scans using Aaro and Dahlborn's technique [17] by a single investigator (BBC). Apical vertebral rotation angle with respect to the sagittal plane (RAsag) was referenced to S1 rotation to normalize variance incurred by patient positioning, as previously described [18-22]. The treating physician, using the standard Adams bend-test position and a Bunnell Scoliometer, prospectively collected all ATI measurements.

Data were tested for normality using the KolmogorovSmirnov test and Levene's test for equality of variance. Descriptive statistics and differences between curve groups were assessed using the two-tailed Student's independent $t$-test. Correlations between variables were calculated with the two-tailed Pearson's product-moment correlation coefficient $(r)$. Significance was set at $\alpha=0.01$.

\section{Results}

Twenty-two of 68 AIS patients treated during this period were identified with apical CT scans performed preoperatively. Of these, 16 females met all inclusion criteria. Median age was 14.6 years $\pm 2.6(11-19)$ and BMI was $19.4 \pm 2.8$ (16-26). Curve patterns represented were: Lenke 1A (4); 1B (1); 2A (3); 2B (1); 2C (1); 3C (1); 4C (1); 5C (3); 6C (1). Twenty-six curves (15 T; 11TL) with complete, date-matched data points were analyzed (Table 1). One thoracic and two thoracolumbar curves were excluded because of missing ATI values, leaving $94 \%$ of eligible $\mathrm{T}$ curves and $85 \%$ of eligible TL curves analyzed.

Table 1 Descriptive statistics of AIS curves, Mean \pm SD (Range)

\begin{tabular}{ccccc}
\hline & Cobb & $\%$ Flexibility & ATI & RAsag \\
\hline Thoracic $(n=15)$ & $63^{\circ} \pm 15.2$ & $35 \% \pm 14.9^{*}$ & $18^{\circ} \pm 5.8+$ & $17^{\circ} \pm 7.1$ \\
& $(29-79)$ & $(11-62)$ & $(6-25)$ & $(5-29)$ \\
Thoracolumbar $(n=11)$ & $48^{\circ} \pm 13.9$ & $59 \% \pm 15.8^{*}$ & $10^{\circ} \pm 5.1 \dagger$ & $18^{\circ} \pm 10.1$ \\
& $(34-78)$ & $(34-82)$ & $(4-20)$ & $(5-41)$ \\
\hline *, Two-tailed Student's independent $t$-test, $p<0.01$. &
\end{tabular}

${ }^{*}+$ Two-tailed Student's independent $t$-test, $p<0.01$.
Mean Cobb angles were T: $63^{\circ} \pm 15.2(29-79)$ and TL: $48^{\circ} \pm 13.9$ (34-78). Mean Cobb flexibility was T: $35 \% \pm$ 14.9 (12-62) and TL: $59 \% \pm 15.8$ (34-82). Mean ATI was T: $18^{\circ} \pm 5.8(6-25)$ and TL: $10.0^{\circ} \pm 5.1$ (4-20). Mean RAsag after normalizing to $\mathrm{S} 1$ rotation was $\mathrm{T}: 17^{\circ} \pm 7.1$ (5-29) and TL: $18^{\circ} \pm 10.1$ (5-41).

When comparing curve groups, thoracolumbar curves had higher percent flexibility $(59.2 \%$ vs. $35 \% ; P<0.01)$ and thoracic curves had larger ATI $\left(18^{\circ}\right.$ vs. $\left.10^{\circ} ; P<0.01\right)$. No other significant differences between curve groups were observed. In thoracic curves, ATI correlated with Cobb $(r=0.711, P<0.004)$ and RAsag $(r=0.730, P<0.003)$. ATI inversely correlated with Cobb flexibility $(r=-0.647$, $P<0.01)$. In thoracolumbar curves, ATI correlated with Cobb $(r=0.789, P<0.005$, ) and RAsag $(r=0.771, P<0.006)$ but not with Cobb flexibility $(r=-0.452, P=0.190)$.

\section{Discussion}

Characterizing the relationships between different measures of scoliosis deformity is important to best understand the disease implications and management choices. Cobb angles are known to correlate with many deformity indices [23] and remain the gold standard for monitoring deformity progression. Historically, coronal and sagittal plane deformity correction have been surgical priorities, however, newer instrumentation systems aim to correct deformities in three planes. Recently, emphasis on correcting apical vertebral rotation in the transverse plane has gained popularity as a method for correcting trunk deformity [24].

Computed tomography is the gold standard for quantifying transverse plane apical vertebral rotation, however, its utility is limited by high radiation exposures and cost. Many trunk deformity indices exist and of these, ATI is widely accepted and used clinically. To date, the relationship between trunk deformity indices and apical vertebral rotation is not well described. The present study is the first attempt to quantify CT-measured vertebral rotation (RAsag) with clinically obtained ATI.

Our findings indicate trunk deformity correlates well with spine deformity and vertebral rotation in both thoracic and thoracolumbar curves. We found slightly stronger correlations in thoracolumbar curves as compared to thoracic, which may be due to restrictions imposed by the associated ribcage. Alternatively, this difference may be an artifact of sample size differences despite the result's significance.

We found a significant negative correlation between ATI and curve flexibility in thoracic curves only. This suggests that as trunk deformity increases, thoracic curves become less flexible. This relationship was not significant in the thoracolumbar region. Our finding is consistent with studies showing thoracic curves are less flexible than thoracolumbar curves in skeletally immature patients [25]. We believe the flexibility mechanisms 
are different in the thoracic and thoracolumbar curves due to the constraints of the associated rib cage in the thoracic spine and our findings support this theory.

A previous study by Grivas et al. found spine and rib cage deformities may not correlate in younger patients [26]. With our small sample size, we are unable to perform reliable subset statistical correlations based on age groups within the thoracic and thoracolumbar groups. It is possible our correlations will not hold true in younger age groups, however, there are many differences in our study worth noting. All of our subjects have surgical-size curves (T: $63^{\circ} \mathrm{TL}: 48^{\circ}$ ), whereas their study was based on screening-size curves (T: $22^{\circ}$ TL: $\left.17^{\circ}\right)$. They analyzed correlations between arbitrarily created age groups, 7-13 yrs and 14-18 yrs. It is unclear how many of their subjects had progressive curves or the clinical significance of their age groupings. Peak Height Velocity more reliably groups patients for maximal curve progression compared to other maturity scales [27]. Our study only included patients with progressive curves requiring spinal arthrodesis and analyzed the correlation between spine and trunk deformities at the point of maximum progression, prior to surgery. It is unknown whether spine and trunk deformities correlate in patients with progressive idiopathic scoliosis when their curve sizes are small, prior to clinically significant progression. It is possible these spine and trunk deformity correlations will differ between patients with progressive and non-progressive AIS and future studies should attempt to answer this question.

Our findings validate previously assumed relationships between vertebral rotation and trunk asymmetry. This finding establishes ATI as a good surrogate measure of vertebral rotation and may decrease the need for CT scans preoperatively in AIS patients. We believe ATI to be a useful clinical measure of scoliosis progression, vertebral rotation, and thoracic curve stiffness in AIS patients with progressive curves.

Our findings are limited by the retrospective design, small sample size, heterogeneous group of curve types, selection-bias during prospective collection, singleobserver radiographic measurements and application in AIS patients with surgical-size curves only. In addition, this study includes both major and compensatory curves, however, all curves were large enough to produce clinically evident trunk asymmetry measureable by a Scoliometer. Inclusion of various curve sizes is important for establishing correlations statistically.

The strengths of this study include date-matched data without missing data points. The senior treating physician used a standardized technique to obtain all ATI measurements prospectively which reduces potential interobserver measurement errors inherent to this measure [28]. Lastly, an investigator not involved in patient care obtained all radiographic measurements.

\section{Conclusions}

Clinically obtained Angle of Trunk Inclination correlates well with coronal Cobb and CT-measured apical vertebral rotation (RAsag) in thoracic and thoracolumbar AIS curves preoperatively. In thoracic curves, ATI negatively correlates with curve flexibility. Clinical use of ATI as a surrogate measure of apical vertebral rotation in un-operated, surgical-size AIS curves may reduce the need for computed tomography, thus reducing radiation exposures and cost.

\section{Abbreviations}

AIS: Adolescent idiopathic scoliosis; ATI: Angle of trunk inclination; T: Thoracic; TL: Thoracolumbar; CT: Computed tomography; RAsag: Rotational angle with respect to the sagittal plane.

\section{Competing interests}

Two of the authors has or had a financial agreement with a commercial company related directly or indirectly to the subject of this research. No financial support was received in direct support of this study. There was no commercial sponsor for this study. All funding for this study was from private research funds.

\section{Authors' contributions}

$M A$ and DB conceived the study. MA and BC collected and maintained the data. $B C$ performed the statistical analyses. MA, DB and BC were all involved in study design, coordination, manuscript drafting and approval of the final manuscript.

Received: 25 October 2012 Accepted: 9 January 2013

Published: 25 January 2013

\section{References}

1. Dubousset J: Three-dimensional analysis of the scoliotic deformity, The pediatric spine: principles and practice. Weinstein SL editionth edition. New York: Raven; 1994:479-496.

2. Cobb J: Outline for the study of scoliosis. Am Acad of Orthop Surg Instr Course Lect 1948, Volume V:261-275.

3. Benson DR, Schultz AB, Dewald RL, Benson DR, Schultz AB, Dewald RL: Roentgenographic evaluation of vertebral rotation. J Bone Joint Surg Am 1976, 58:1125-1129.

4. Bunnell WP: Vertebral rotation: simple method of measurment on routine radiographs. Orthop Trans 1985, 9:114.

5. Nash CL Jr, Moe JH, Nash CL Jr, Moe JH: A study of vertebral rotation. J Bone Joint Surg Am 1969, 51:223-229.

6. Perdriolle R, Vidal J, Perdriolle R, Vidal J: Morphology of scoliosis: threedimensional evolution. Orthopedics 1987, 10:909-915.

7. Stokes IA, Bigalow LC, Moreland MS, Stokes IA, Bigalow LC, Moreland MS: Measurement of axial rotation of vertebrae in scoliosis. [see comment] [erratum appears in Spine. May;16(5):599-60; PMID: 2053012]. Spine 1991, 1986(11):213-218.

8. Suzuki S, Yamamuro T, Shikata J, Shimizu K, lida H, Suzuki S, Yamamuro T, Shikata J, Shimizu K, lida H: Ultrasound measurement of vertebral rotation in idiopathic scoliosis. J Bone Joint Surg Br 1989, 71:252-255.

9. Birchall D, Hughes DG, Hindle J, Robinson L, Williamson JB, Birchall D, Hughes DG, Hindle J, Robinson L, Williamson JB: Measurement of vertebral rotation in adolescent idiopathic scoliosis using three-dimensional magnetic resonance imaging. Spine 1997, 22:2403-2407.

10. Gocen S, Aksu MG, Baktirolu L, Ozcan O, Gocen S, Aksu MG, Baktirolu L, Ozcan O: Evaluation of computed tomographic methods to measure vertebral rotation in adolescent idiopathic scoliosis: an intraobserver and interobserver analysis. J Spinal Disord 1998, 11:210-214.

11. Ho EK, Upadhyay SS, Ferris L, Chan FL, Bacon-Shone J, Hsu LC, Leong JC, Ho EK, Upadhyay SS, Ferris $L$, et al: A comparative study of computed tomographic and plain radiographic methods to measure vertebral rotation in adolescent idiopathic scoliosis. Spine 1992, 17:771-774.

12. Krismer $M$, Chen AM, Steinlechner $M$, Haid C, Lener M, Wimmer C, Krismer M, Chen AM, Steinlechner M, Haid C, et al: Measurement of vertebral rotation: a comparison of two methods based on CT scans. J Spinal Disord 1999, 12:126-130. 
13. Majdouline $Y$, Aubin CE, Robitaille M, Sarwark JF, Labelle H: Scoliosis correction objectives in adolescent idiopathic scoliosis. J Pediatr Orthop 2007, 27:775-781.

14. Patias P, Grivas TB, Kaspiris A, Aggouris C, Drakoutos E: A review of the trunk surface metrics used as Scoliosis and other deformities evaluation indices. Scoliosis 2010, 5:12

15. Bunnell WP, Bunnell WP: An objective criterion for scoliosis screening. J Bone Joint Surg Am 1984, 66:1381-1387.

16. Lenke LG, Betz RR, Harms J, Bridwell KH, Clements DH, Lowe TG, Blanke K, Lenke LG, Betz RR, Harms J, et al: Adolescent idiopathic scoliosis: a new classification to determine extent of spinal arthrodesis.[see comment]. $J$ Bone Joint Surg Am 2001, 83-A:1169-1181.

17. Aaro S, Dahlborn M: Estimation of vertebral rotation and the spinal and rib cage deformity in scoliosis by computer tomography. Spine 1981, 6:460-467.

18. Lee SM, Suk SI, Chung ER: Direct vertebral rotation: a new technique of three-dimensional deformity correction with segmental pedicle screw fixation in adolescent idiopathic scoliosis. Spine 2004, 29:343-349.

19. Gondo $\mathrm{H}$ : Evaluation of spine and thoracic cage configuration change following Isola spinal instrumentation of adolescent idiopathic scoliosis (in Japanese; tables and abstract in English). J Jpn Scoliosis Soc 1996, 11:75-84.

20. Gondo $\mathrm{H}$, Asher M: Mid-term effects of Isola instrumentation on the configuration of the spine and the thoracic cage in adolescent idiopathic scoliosis. In Research into spinal deformities 1. Edited by Sevastik J, Diab K. Amsterdam: Ios Press; 1997:433-436.

21. Wood KB, Olsewski JM, Schendel MJ, Boachie-Adjei O, Gupta M, Wood KB, Olsewski JM, Schendel MJ, Boachie-Adjei O, Gupta M: Rotational changes of the vertebral pelvic axis after sublaminar instrumentation in adolescent idiopathic scoliosis. Spine 1997, 22:51-57.

22. Wood KB, Transfeldt EE, Ogilvie JW, Schendel MJ, Bradford DS, Wood KB, Transfeldt EE, Ogilvie JW, Schendel MJ, Bradford DS: Rotational changes of the vertebral-pelvic axis following Cotrel-Dubousset instrumentation. Spine 1991, 16:S404-S408.

23. Kuklo TR, Potter BK, Lenke LG, Kuklo TR, Potter BK, Lenke LG: Vertebral rotation and thoracic torsion in adolescent idiopathic scoliosis: what is the best radiographic correlate? J Spinal Disord Tech 2005, 18:139-147.

24. Hwang SW, Samdani AF, Cahill PJ: The impact of segmental and en bloc derotation maneuvers on scoliosis correction and rib prominence in adolescent idiopathic scoliosis. J Neurosurg Spine 2012, 16:345-350

25. Chen ZQ, Zhao YF, Bai YS, Liu KP, He SS, Wang CF, Zhang JT, Li M: Factors affecting curve flexibility in skeletally immature and mature idiopathic scoliosis. J Orthop Sci 2011, 16:133-138.

26. Grivas TB, Vasiliadis ES, Mihas C, Savvidou O: The effect of growth on the correlation between the spinal and rib cage deformity: implications on idiopathic scoliosis pathogenesis. Scoliosis 2007, 2:11.

27. Little DG, Song KM, Katz D, Herring JA: Relationship of peak height velocity to other maturity indicators in idiopathic scoliosis in girls. J Bone Joint Surg Am 2000, 82:685-693.

28. Cote P, Kreitz BG, Cassidy JD, Dzus AK, Martel J: A study of the diagnostic accuracy and reliability of the Scoliometer and Adam's forward bend test. Spine 1998, 23:796-802. discussion 803

doi:10.1186/1748-7161-8-2

Cite this article as: Carlson et al:: Comparison of trunk and spine deformity in adolescent idiopathic scoliosis. Scoliosis 2013 8:2.

\section{Submit your next manuscript to BioMed Central and take full advantage of:}

- Convenient online submission

- Thorough peer review

- No space constraints or color figure charges

- Immediate publication on acceptance

- Inclusion in PubMed, CAS, Scopus and Google Scholar

- Research which is freely available for redistribution 